\title{
Social Media and Environmental Sustainability: An Overview of European Countries
}

\author{
Federica De Leo ${ }^{1}$, Ginevra Gravili ${ }^{1} \&$ Pier Paolo Miglietta ${ }^{1}$ \\ ${ }^{1}$ Department of Management and Economics, University of Salento, Italy \\ Correspondence: Federica De Leo, Department of Management and Economics, University of Salento, Via per \\ Monteroni, Lecce, 73100, Italy. E-mail: federica.deleo@unisalento.it
}

Received: March 11, 2016

Accepted: April 5, 2016

Online Published: May 25, 2016

doi:10.5539/ijbm.v11n6p1

URL: http://dx.doi.org/10.5539/ijbm.v11n6p1

\begin{abstract}
The theme of the relationship between social media and sustainability has prompted many scholars to analyze the impact that "virtual information" has on the environment. This study empirically tests two models that examine the effects of cultural values and social media on environmental performance by considering different variables such as Social Media penetration, Hofstede's Cultural Dimensions and Environmental Performance Index. Two multiple linear regression models were employed to test the hypotheses on a sample of 30 European Countries.

Empirical results, extensible to all of Europe, conclude that the cultural dimensions analyzed, as well as social media penetration, significantly influence environmental performance of European Countries when we execute a combined model.

Social media are arguably an integral part of sustainability strategy and future research on IT and sustainability needs to take a more integrated approach. If we consider that social media have a positive effect on the environment it is easy to intuit that if governance implements effective policies to ensure social media access for everyone, real sustainable development could be achieved.
\end{abstract}

Keywords: information technologies, social media, environmental performance index

\section{Introduction}

Today the evolution of Information Technologies is opening new scenarios even in sustainability systems: the virtual revolution announces a new model of society in which the concepts of sustainable development could radically change managerial imperatives, structures, processes and organizational cultures.

The increasingly pressing need to preserve the environment as a source of exhaustible natural resources has led to promoting socio-economic models that are more balanced than those adopted in the past. Today organizations, complex adaptive systems, are becoming open and collaborative systems, capable of developing places, especially virtual ones, where new "distinctive" knowledge is created, knowledge that spreads through relational assets that are established between the human components. The communication process, therefore, takes a central role. Communication alone, however, is not able to carry out all its connection, accumulation, diffusion and sharing capacity developing "the needs of the present without compromising the ability of future generations to meet their own needs" (Burton, 1987). On the contrary, it requires social and organizational intelligence, as well as the abandonment of traditional interpretations of organizational phenomena opting rather for an approach that takes into account the new communicational models that emphasize the interaction and cooperation amongst individuals and groups and, consequently, of the social innovation geared towards the fulfillment of a long-lasting sustainable competitive advantage.

From this perspective, what has captured our interest in this research is the fact that a complex and profoundly articulated relationship exists uniting "communication, culture and sustainability".

The choice of communication styles depends on cognitive differences reflected in cultural diversity (Richman, 2002). In actual fact, Information Technologies modify the mental attitudes of individuals from an extremely early age freeing them from the "proxemic" components typical of "face to face" communication. Besides, if it is true that the possible ways through which there is the chance to communicate, can be influenced by the context which, in turn, may be planned with intention, it would be interesting to understand how culture and social media 
could modify such processes and how a real incorporation of the social aspects of sustainability could take place (Carter \& Rogers, 2008).

New styles and new contents in the communication system are required to develop sustainability, both because they allow us to communicate the progress towards sustainability (and the new social media have low costs and unlimited access) and because the pre-condition for sustainability is transparency, and social media are the tool to making the transparency practicable.

Today, to create a better and more harmonious world it would be useful to develop models that may allow for operation in a time-space dimension, which is apparently unlimited and where culture and communication are the instruments that spread common intelligence and socially sustainable inclusive development.

\section{Conceptual Model and Hypotheses}

Previous studies have focused on finding relationships between sustainable development and competitiveness (Riasi, 2015; Riasi \& Amiri Aghdaie, 2013; Riasi \& Pourmiri, 2016). According to these studies, it is now widely accepted that firms who pay more attention to sustainable development are more competitive in their businesses in the long term (Ansari \& Riasi, 2016; Riasi \& Pourmiri, 2016).

The concept of sustainability, that we adopt, is the concept of Triple Bottom Line (TBL), which considers organizational sustainability to include three components: the natural environment, society and economic performance (Elkington, 1994; Elkington, 2004).

The triple bottom line has evolved as an alternative to the idea of company success based on economic factors alone (Granados \& Gamez, 2010) and considers organizational sustainability to include, besides economic components, also social and environmental ones.

Little research has examined the role of IT resources in enabling firms to develop capabilities to address TBL issues. In practice, the major contributions of IT to sustainability have been centered on reducing IT's energy consumption through green IT initiatives. Given the recognized role of IT resources in enabling business capabilities, it is arguable that IT resources should be critical in enabling firms to develop capabilities to address TBL issues and gain a sustained competitive advantage. However, insight on such issues is limited (Dao et al., 2011).

So, if we consider that the use of social media communication differs among cultures since the choice of a specific form of communication can signify a differential level of formality, respect, familiarity or intimacy (Richardson \& Smith, 2007), it's simple to understand that the communication method adopted by an individual belonging to a specific culture can be read as the result of reasoning which derives from the perception of the sustainability and which has relevant effects on the implementation of the use of this new communication tool.

If we adopt this kind of observation lens, we could consider social communication and culture as useful keys for analyzing the sustainability of a country and, therefore, a valuable starting point to help to create a better and more harmonious world.

We define a pilot project, starting from the existing literature on the relationship between cultural diversity and environmental sustainability (Husted, 2005), and introduce a new variable, social media, to measure and compare its positive or negative effect on environmental sustainability. The use of social media, allowing for an instant sharing of ideas, opinions, knowledge and experiences, creates a new "space-time" dimension that translates into a new capacity of countries to implement a communicative system that is readily accessible to everyone (Castella \& Verburg, 2007; Fürst et al., 2010; Mendoza \& Martins, 2006).

This new form of communication, providing simpler processes and developing a transparent access to information, can ensure sustainable environmental development.

The basic idea of the model was to build a conceptual bridge between the use of social media and cultural diversity in different European Countries and environmental sustainability.

We have elaborated an integrated conceptual model (Figure 1), which matches the model of Husted (Husted, 2005) and social media. Husted's study analyzes the impact of Hofstede's classic cultural dimensions on environmental sustainability, recognizing this as one of the most widely conceptual frameworks of cultural diversity. Hofstede's classic survey has identified five cultural dimensions: Power Distance (PDI) refers to the degree to which the persons living in a society accept an unequal distribution of power and perceive hierarchies as something natural. Individualism (IDV) defines whether people in a society think in terms of "I" or "we". This means that people rely on the care of the groups they belong to, but in return these groups demand total loyalty from them. Masculinity (MAS) questions if the individuals in a society act more competitively or rather 
seek consensus. Individuals in a feminine society tend to be modest in terms of not boasting about their wealth for example. Moreover, they are more strongly engaged in care taking. Uncertainty Avoidance (UAI) describes how societies deal with the fact that the future cannot be known. Cultures with a high level of uncertainty avoidance try to control the future and avoid risks. They have a certain code for how to deal with uncertain situations. Countries with a low level of uncertainty avoidance have a more relaxed attitude towards this issue.

In 1991 Bond, supported by Hofstede, identified the Long-Term Orientation (LTO) variable, which indicates the temporal planning horizon. Societies that plan in the long term tend to be more thrifty and persistent while short-term orientated societies are rather flexible and egoistic.

In 2010, Minkov added two new dimensions: pragmatism and indulgence. On one hand, the dimension of Bond and Minkow correlate strongly, yet the constructs are not fully identical. The country scores used in this paper are the scores of Minkov's research. We refer to this fifth dimension as Pragmatic versus Normative (PRA). Pragmatism indicates if a culture is more pragmatic and accepts the facts of life and makes the best out of it while if people feel the desire to find explanations for everything around them this, in contrast, is called normative. Indulgence, whose opposite is restraint, determines the degree to which the members of a society see enjoying life as a major part of living. According to this, members of a restrained society, instead, suppress the need to gratify their desires. In 2011, Hofstede included research results of Minkov in his model (Hofstede's advanced model).

Our model aims at providing an integrated theoretical model to analyze environmental sustainability of 30 European countries in relationship to their use of social media and to the culture of each country to understand if social media and culture influence environmental sustainability.

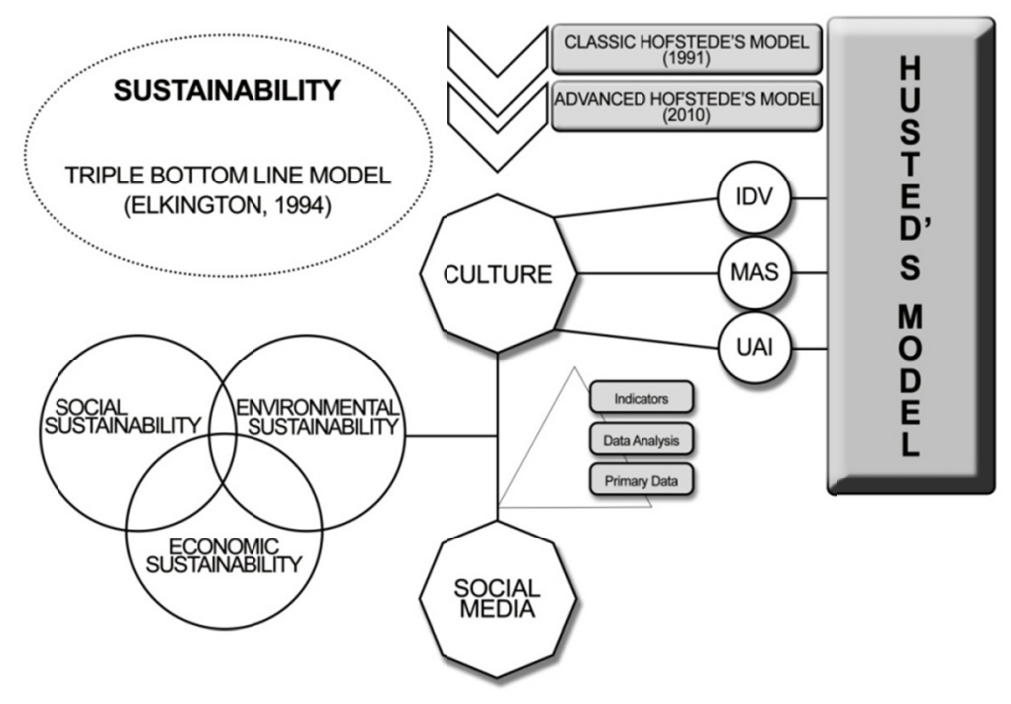

Figure 1. Conceptual model

We hypothesize that:

Hypothesis 1. The culture and the use of Information technology, in particular of Social Media, affect environmental sustainable performances of Countries.

Hypothesis 2. The relation between Environmental sustainable performances of Countries and Social media penetration is positive and relevant.

\section{Material and Methods}

On the basis of literature review and hypothesis construction, the research proposes two multiple regression models for statistical testing. The underlying assumption is that Social Media penetration, Gross National Income, and Hofstede's cultural dimensions are uncorrelated to the Environmental Performance Index.

Our first model is based on the following regression, considering as regressors the classical Hofstede's dimensions (Hofstede, 1991), Social Media penetration and Gross National Income: 


$$
E P I=\beta_{1} S M+\beta_{2} G N I+\beta_{3} P D I+\beta_{4} U A I+\beta_{5} M A S+\beta_{6} I D V+u
$$

$\beta_{1}=$ coefficient of the SM, i.e. effect on EPI of a change in SM, holding PDI, GNI, UAI, MAS and IDV constant;

$\beta_{2}=$ coefficient of the GNI, i.e. effect on EPI of a change in GNI, holding SM, PDI, UAI, MAS and IDV constant;

$\beta_{3}=$ coefficient of the PDI, i.e. effect on EPI of a change in PDI, holding SM, GNI, UAI, MAS and IDV constant;

$\beta_{4}=$ coefficient of the UAI, i.e. effect on EPI of a change in UAI, holding SM, GNI, PDI, MAS and IDV constant;

$\beta_{5}=$ coefficient of the MAS, i.e. effect on EPI of a change in MAS, holding SM, GNI, PDI, UAI and IDV constant;

$\beta_{6}=$ coefficient of the IDV, i.e. effect on EPI of a change in IND, holding SM, GNI, PDI, UAI and MAS constant;

$\mathrm{u}=$ errors due to omitted variables.

Our second model is based on the following regression, considering as regressors also the new Hofstede's dimensions (Hofstede et al., 2010), Social Media penetration and Gross National Income:

$$
E P I=\delta_{1} S M+\delta_{2} G N I+\delta_{3} P D I+\delta_{4} U A I+\delta_{5} M A S+\delta_{6} I D V+\delta_{7} I N D+\delta_{8} P R A+u
$$

$\delta_{1}=$ coefficient of the SM, i.e. effect on EPI of a change in SM, holding PDI, GNI, UAI, MAS, IDV, IND e PRA constant;

$\delta_{2}=$ coefficient of the GNI, i.e. effect on EPI of a change in GNI, holding SM, PDI, UAI, MAS, IDV, IND and PRA constant;

$\delta_{3}=$ coefficient of the PDI, i.e. effect on EPI of a change in PDI, holding SM, GNI, UAI, MAS, IDV, IND and PRA constant;

$\delta_{4}=$ coefficient of the UAI, i.e. effect on EPI of a change in UAI, holding SM, GNI, PDI, MAS, IDV, IND and PRA constant;

$\delta_{5}=$ coefficient of the MAS, i.e. effect on EPI of a change in MAS, holding SM, GNI, PDI, UAI, IDV, IND and PRA constant;

$\delta_{6}=$ coefficient of the IDV, i.e. effect on EPI of a change in IND, holding SM, GNI, PDI, UAI, MAS, IND and PRA constant;

$\delta_{7}=$ coefficient of the IND, i.e. effect on EPI of a change in MAS, holding SM, GNI, PDI, UAI, MAS, IDV and PRA constant;

$\delta_{8}=$ coefficient of the PRA, i.e. effect on EPI of a change in IND, holding SM, GNI, PDI, UAI, MAS, IDV and IND constant;

$\mathrm{u}=$ errors due to omitted variables.

The Ordinary Least Squares Estimator minimizes the average squared difference between the actual values of EPI and the predicted value based on the estimated line.

The research design adopted is secondary data analysis and the elementary units of analysis are European Countries. A set of 30 European Countries was selected among Countries whose indicators chosen for this research had previously been evaluated (Appendix). Existing quantitative databases have been used as data sources. We first obtained country-level data of Environmental Performance Index (EPI) from the Environmental Performance Index report (Yale University, 2014) and excluded those Countries not included in Hofstede's Country list (Hofstede, 2014). Finally, we collected these Countries' Gross National Income and Social Media penetration data respectively from World Bank database (World Bank, 2014) and WeAreSocial report (We are Social, 2014). The data collected for Gross National Income, Environmental Performance Index and Social Media penetration are all from the year 2014. Hofstede's scores on national culture are considered to be relatively stable over time and are still used in numerous publications.

The dependent variable, that is EPI, represents, on a theoretical plane, the environmental sustainability performance of Countries. The Environmental Performance Index (EPI) is a method for quantifying and numerically benchmarking the environmental performance of a country's policies (Duasa \& Afroz, 2013). 
The EPI was preceded by the Environmental Sustainability Index (ESI) with the aim of launching a complementary tool to the Millennium Development Goals (MDGs) and a counterpoint to gross domestic product (GDP), which, for too long, had been the sole measure of wellbeing.

The ESI was a first attempt to rank countries on 76 different elements of environmental sustainability, including natural resource endowments, past and present pollution levels, environmental management efforts, contributions to the protection of the global commons, and a society's capacity to improve environmental performance over time (Yale University, 2005).

The index assigns scores to each country based on two key objectives: 1) environmental health which refers to the extent to which deficiencies in water quality, air pollution and other factors cause health issues and a decrease in quality of life; 2) Ecosystem vitality which measures the health of a country's ecosystem by evaluating such factors as agriculture, climate change, fisheries, and forestry (Onel \& Mukherjee, 2014).

Data sources for the Environmental Performance Index derive from international organizations, research institutions, and government agencies and include:

- official statistics that are measured and formally reported by governments to international organizations that may or may not be independently verified;

- spatial data compiled by research or international organizations;

- observations from monitoring stations;

- modeled data.

In particular, the data on the Environmental Performance Index for our purpose (Appendix) have been extracted from the EPI Full report 2014 (Yale University, 2014). The spatial distribution of the data relating to the Environmental Performance Index is fairly uniform, not showing significant variability among values. A divergence between North-Western European Countries that show better environmental performance and South-Eastern Countries with relatively lower values is evident.

The measures of cultural variables related to Hofstede's three cultural dimensions of Individualism, Masculinity and Uncertainty Avoidance have been extracted from Hofstede's database (Hofstede, 2014). Hofstede measures of culture are widely cited and used by many scholars.

Individualism (IND) describes the level of integration of people into groups. According to this dimension there are individualistic and collectivistic societies.

Masculinity (MAS) refers to the distribution of roles between the genders. The most relevant values of masculine cultures are competitiveness, assertiveness, materialism, ambition and power.

According to Hofstede, the uncertainty avoidance dimension (UAI) deals with the national culture's ability to tolerate ambiguity. Individuals in these high uncertainty avoidance cultures tend to be rigid and dogmatic (Baker \& Carson, 2011).

In Hofstede's new framework (Hofstede et al., 2010) two new dimensions have been introduced.

One of these is referred to as "(short term) normative versus (long term) pragmatic" (PRA). Every society has to maintain some links with its own past while dealing with the challenges of the present and the future. Societies prioritize these two existential goals differently.

The second one called "indulgence" (IND), instead, represents a society that allows relatively free gratification of basic natural human desires related to enjoying life and having fun. Restraint stands for a society that suppresses gratification of these needs and regulates it by means of strict social norms (Hofstede et al., 2010).

Social Media penetration (SM) data (Figure 4) have been extracted from Social, Digital \& Mobile Worldwide reports in We Are Social's series (We are Social, 2014).

At the start of 2014, Europe boasted almost 300 million active social media users, accounting for $40 \%$ of the region's population. However, when it comes to platforms of choice, the social media landscape in Europe is split in two. Facebook dominates in Western Europe, with 37 countries around the region accounting for a total of 232.2 million active users - roughly $19 \%$ of the platform's total global user base. To put this in perspective, these countries account for less than $8 \%$ of the total world population.

However, Eastern Europe is still a VKontakte stronghold, with users in Russia, Ukraine and Belarus accounting for more than 60 million active accounts.

As with Internet penetration, Iceland also leads the way in terms of social media penetration, with $70 \%$ of the 
country's population using Facebook in the past month. Malta puts in an impressive showing at $58 \%$ penetration, with the Scandinavian countries rounding out the rest of the top 5.

Gross National Income (GNI) per capita based on Purchasing Power Parity (PPP) represents a control variable. GNI is gross national income (GNI) converted to international dollars using purchasing power parity rates. An international dollar has the same purchasing power over GNI as a U.S. dollar has in the United States. GNI is the sum of value added by all resident producers plus any product taxes (less subsidies) not included in the valuation of output plus net receipts of primary income (compensation of employees and property income) from abroad. Data are in current international dollars based on the 2011 ICP round.

\section{Data Analysis and Results}

The output that we get from data processing through software Gretl, on the basis of our conceptual model, is indicated below (Table 1).

Table 1. Ordinary least squares estimator for the empirical models proposed

\begin{tabular}{lll}
\hline Variables & First Model & Second model \\
\hline SM & $0.494593^{* * *}$ & $0.543829^{* * *}$ \\
& $(0.146646)$ & $(0.183042)$ \\
GNI & $0.000422406^{*}$ & 0.000394083 \\
& $(0.000240211)$ & $(0.000267587)$ \\
PDI & 0.0227521 & -0.0346733 \\
& $(0.105764)$ & $(0.104928)$ \\
UAI & $0.230641^{* * *}$ & $0.215973^{* *}$ \\
& $-0,0786381$ & $(0.0825023)$ \\
MAS & $0.116661^{*}$ & 0.0999274 \\
& $(0.0623966)$ & $(0.067842)$ \\
IDV & $0.235006^{*}$ & 0.148664 \\
IND & $(0.116853)$ & $(0.114516)$ \\
& & 0.00986032 \\
PRA (LTO) & & $(0.177781)$ \\
$\mathrm{R}^{2}$ & & 0.138291 \\
$\mathrm{R}^{2}$ Adjusted & & $(0.104248)$ \\
\hline
\end{tabular}

standard errors of coefficients in parentheses.

$* * *=1 \%$ significance level.

Adjusted $\mathrm{R}^{2}$ is used in place of the simple $\mathrm{R}^{2}$ because as the number of explanatory variables increases, simple $\mathrm{R}^{2}$ increases too. Given that adjusted $\mathrm{R}^{2}$ is used as the main index of the goodness of the regression curve, for the analysis of multiple linear regression, measuring the fraction of deviance explained, i.e. the proportion of the variability of $\mathrm{Y}$ explained by independent variables $\mathrm{X}$, we can affirm that the regression model proposed explains approximately the $98 \%$ of the variation in the EPI, so our Hypothesis 1 can be accepted.

Conducting the test on the normality of the residues proposed by Jarque and Bera the p-value associated with the test statistic is equal to 0.1053 for our first model and 0.0773 for the second one. Therefore, for both models, we accept the null hypothesis that errors are distributed normally, i.e. the distribution of residuals from regressions is likely to be Gaussian (Figure 2-3). 


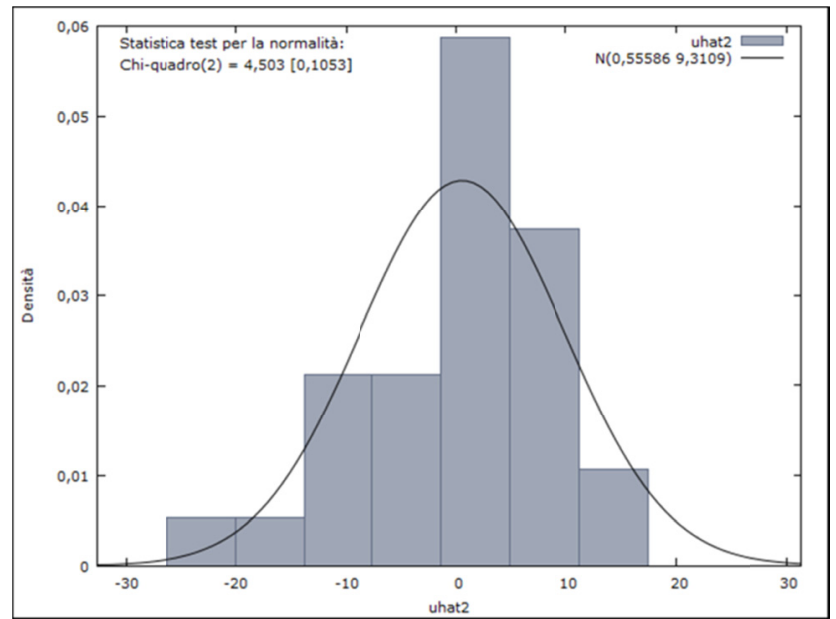

Figure 2. Test-statistics for normalization (first empirical model)

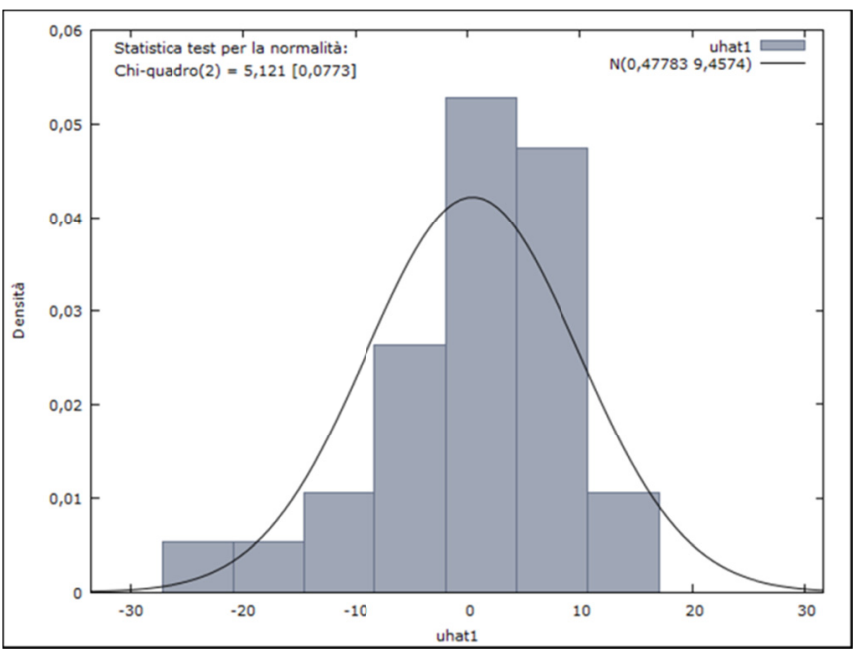

Figure 3. Test-statistics for normalization (second empirical model)

As regards, instead, heteroskedasticity, it makes no sense to conduct a test, since, in the estimation of the model we have considered the function of robust standard errors. Standardizing the variables, results in terms of goodness of the model do not change.

Turning to the interpretation of the coefficients, it is clear that in the light of the values of $\beta_{1}$ and $\delta_{1}$, the increase of 1 in the Social media penetration index, keeping all other factors constant (ceteris paribus), increases the Environmental Performance Index in both the models of 0.494593 and 0.543829 .

The values of $\beta_{1}$ and $\delta_{1}$ emphasize a positive relationship between the dependent variable Environmental Performance Index and the independent variable Social media penetration, with all other variables held constant. The p-value of the two models equalling, respectively, 0.0025 and 0.0071 , also implies a relevant significance of these results, fully demonstrating our Hypothesis 2.

The correlation between the two indices is positive, meaning that a wide use social media and IT in general tend to coincide with high Environmental Performance Index values, showing the capability of Information technology to influence and measure certain aspects of environmental sustainability (Dao et al., 2011).

As regards cultural variables, our models confirm the results of previous scientific literature (Husted, 2005), showing an influence of cultural variables on environmental sustainability, especially analysing the first model which, as already mentioned, considers only the classical Hofstede's cultural variables.

Moreover, the results obtained by this study demonstrate a non-significant contribution of the power distance index to the EPI and a particularly significant linkage between uncertainty avoidance index and environmental 
sustainability.

In order to evaluate the efficiency of the multiple linear regression models identified, we have conducted the F-test to assess the significance of the model, to verify if there is a significant relationship between the dependent variable and the set of explanatory variables.

In particular, this test is based on the F statistic generated by the ratio of the mean square regression (known as variance of regression) and the mean square error (known as residual variance). By using this test it is possible to verify (null hypothesis) if the variance of residuals is due to the regression errors. This statistic follows a distribution $\mathrm{F}$ of Fisher.

In this study, the values assumed by the F statistic are equal to 323.6663 (first model) and 254.2257 (second model) and the associated p-values are lower than the critical probability value $\alpha=0.05$. Therefore, at a significance level of $5 \%$, it is possible to reject the null hypothesis and to conclude that the multiple regression models herein identified are statistically significant, since, in both cases, at least one independent variable significantly influences the dependent variable (EPI).

\section{Discussion and Conclusion}

Unforeseeable success of social media, in the last few years, has required organizations to be present in places where people connect and share knowledge. Our survey has shown that there is a positive correlation between social media and environmental sustainability and that social media influence environmental sustainability more than 50\% (Hypothesis 2). This value is similar in all analyzed European countries (Hypothesis 1).

These results lay the theoretical foundation for future research on the sustainability value of social media in several ways. First, our research has shown that the contributions of social media to sustainability go beyond reducing I.T.'s energy consumption through green I.T. initiatives, placing them in a broader sustainability framework. Investments in social media for sustainability must be aligned with other complementary business resources - here, HRM and SCM resources - to enable firms to achieve sustainability targets. Thus, social media are arguably an integral part of firms' sustainability strategy and future research on IT and sustainability needs to take a more integrated approach, examining IT resources and strategies that are integrated with complementary business resources and strategies, and aligned with the situational context (cultural diversity) to enable firms to develop sustainability capabilities for specific sustainability objectives.

It is an important result that requires an organizational change and, at the same time, new ways of rethinking policy: new roles, new work processes and new organizational structures. All this means investing in adequately shaped human resources which are able to manage the relationship with the customer efficiently, allowing to develop effective and efficient one-to-many, many-to-one or many-to-many relationships. In this way, customers have a say on the matter: by expressing positive opinions on the site they create an improvement to the image of the organizations and the human resources that operate within it, reaching competitive advantages which, in the long run, are transformed into sustainable advantages.

Today, environmental sustainability is one of the major challenges on a global level and as a result is one of the priority objectives of the European Union which, since the early $70 \mathrm{~s}$, has established Community rules on environmental policies designed to encourage companies to develop "green" economy. The main objective of European environmental policy is to enhance natural resources, promote an economy based on the efficient use resources and protect the health of people. EU Countries are required to consider environmental aspects, not only to comply with regulations, but also to structure their growth in a sustainable way, preserving their competitiveness on the global market.

Then, if we consider that social media have a positive effect on environment it is easy to intuit that if governance implements effective policies to ensure social media access for everyone, real sustainable development could be achieved.

\section{References}

Ansari, A., \& Riasi, A. (2016). An Investigation of Factors Affecting Brand Advertising Success and Effectiveness. International Business Research, 9(4), 20-30. http://dx.doi.org/10.5539/ibr.v9n4p20

Baker, D. S., \& Carson, K. D. (2011). The Two Faces of Uncertainty Avoidance: Attachment and Adaptation. The Journal of Behavioral and Applied Management, 12(2), 128-141.

Burton, I. (1987). Report on Reports: Our Common Future: The World Commission on Environment and Development. Environment: Science and Policy for Sustainable Development, 29(5), 25-29. http://dx.doi.org/10.1080/00139157.1987.9928891 
Carter, C. R., \& Rogers, D. S. (2008). A framework of sustainable supply chain management: Moving toward new theory. International Journal of Physical Distribution \& Logistics Management, 38(5), 360-387. http://dx.doi.org/10.1108/09600030810882816

Castella, J. C., \& Verburg, P. H. (2007). Combination of process-oriented and pattern-oriented models of land-use change in a mountain area of Vietnam. Ecological Modelling, 202(3), 410-420. http://dx.doi.org/10.1016/j.ecolmodel.2006.11.011

Dao, V., Langella, I., \& Carbo, J. (2011). From green to sustainability: Information Technology and an integrated sustainability framework. The Journal of Strategic Information Systems, 20(1), 63-79. http://dx.doi.org/10.1016/j.jsis.2011.01.002

De Leo, F., \& Miglietta, P. P. (2015). The Contribution of Environmental Indicators to the Sustainable Performance of Countries. International Journal of Sustainability Policy and Practice, 11(4), 12-26. Retrieved from http://ijspp.cgpublisher.com/product/pub.274/prod.112

Duasa, J., \& Afroz, R. (2013). Modeling Environmental Performance and Economic Development. International Journal of Trade, Economics \& Finance, 4(6), 384-387. http://dx.doi.org/10.7763/IJTEF.2013.V4.322

Elkington, J. (1994). Towards the Sustainable Corporation: Win-Win-Win Strategies for Sustainable Development. California Management Review, 36(2), 90-100. http://dx.doi.org/10.2307/41165746

Elkington, J. (2004). Enter the Triple Bottom Line. In A. Henriques \& J. Richardson (Eds.), The Triple Bottom Line: Does It All Add Up? (pp. 1-17). London, UK: Earthscan.

Fürst, C., Pietzsch, K., Lorz, C., \& Makeschin, F. (2010). Integration of Environmental Processes into Land-use Management Decisions. Process Management, 269-284. http://dx.doi.org/10.5772/8440

Granados, A. C., \& Gamez, G. G. (2010). Sustainability and triple bottom line: Key issues for successful Spanish school principals. International Journal of Educational Management, 24(6), 467-477. http://dx.doi.org/10.1108/09513541011067656

Hofstede, G. (1991). Cultures and organizations: Software of the mind. New York, NY: McGraw-Hill.

Hofstede, G. (2014). The Hofstede centre-Dimensions. Retrieved from http://geert-hofstede.com/dimensions.html

Hofstede, G., Hofstede, G. J., \& Minkov, M. (2010). Cultures and Organizations: Software of the Mind (3rd ed.). New York, NY: McGraw-Hill.

Husted, B. W. (2005). Culture and ecology: A cross-national study of the determinants of environmental sustainability. MIR: Management International Review, 349-371. Retrieved from http://www.jstor.org/stable/40836056

Mendoza, G. A., \& Martins, H. (2006). Multi-criteria decision analysis in natural resource management: A critical review of methods and new modelling paradigms. Forest Ecology and Management, 230(1), 1-22. http://dx.doi.org/10.1016/j.foreco.2006.03.023

Onel, N., \& Mukherjee, A. (2014). The effects of national culture and human development on environmental $\begin{array}{lllll}\text { health. Environment, Development and } & \text { Sustainability, 161), }\end{array}$ http://dx.doi.org/10.1007/s10668-013-9464-y

Riasi, A. (2015). Competitive Advantages of Shadow Banking Industry: An Analysis Using Porter Diamond Model. Business Management and Strategy, 6(2), 15-27. http://dx.doi.org/10.5296/bms.v6i2.8334

Riasi, A., \& Amiri Aghdaie, S. F. (2013). Effects of a Hypothetical Iranian Accession to the World Trade Organization on Iran's Flower Industry. Consilience: The Journal of Sustainable Development, 10(1), 99-110. http://dx.doi.org/10.7916/D8HQ3ZK8

Riasi, A., \& Pourmiri, S. (2016). Examples of Unsustainable Tourism in Middle East. Environmental Management and Sustainable Development, 5(1), 69-85. http://dx.doi.org/10.5296/emsd.v5i1.8705

Richardson, R. M., \& Smith, S. W. (2007). The influence of high/low-context culture and power distance on choice of communication media: Students' media choice to communicate with professors in Japan and America. International Journal of Intercultural Relations, 31(4), 479-501. http://dx.doi.org/10.1016/j.ijintrel.2007.01.002

Richman, L. (2014). Project management step-by-step. New York, NY: AMACOM Books: 2002 Hofstede, G., "The Hofstede centre-Dimensions". Retrieved from http://geert-hofstede.com/dimensions.html

We are Social. (2014). Social, Digital \& Mobile in Europe in 2014. Retrieved from http://wearesocial.net/blog/2014/02/social-digital-mobile-europe-2014/ 
World Bank. (2014). GNI per capita, PPP (current international \$). Retrieved from http://data.worldbank.org/indicator/NY.GNP.PCAP.PP.CD

Yale University. (2005). Comparing the ESI with Other Sustainability Indicators. Retrieved from http://www.yale.edu/esi/f_comparing.pdf

Yale University. (2014). Environmental Performance Index Full report 2014. Retrieved from http://epi.yale.edu/files/2014_epi_report.pdf

Appendix. Dataset used for the empirical analysis

\begin{tabular}{|c|c|c|c|c|c|c|c|c|c|}
\hline Country & EPI Score & PDI & Social Media & Individualism & Masculinity & Uncertainity & Pragmatism & Indulgence & GNI (PPP) \\
\hline Switzerland & 87.67 & 34 & 43 & 68 & 70 & 58 & 74 & 66 & 56,580 \\
\hline Czech Republic & 81.47 & 57 & 41 & 58 & 57 & 74 & 70 & 29 & 25,530 \\
\hline Germany & 80.47 & 35 & 35 & 67 & 66 & 65 & 83 & 40 & 44,540 \\
\hline Spain & 79.79 & 57 & 41 & 51 & 42 & 86 & 48 & 44 & 31,850 \\
\hline Austria & 78.32 & 11 & 39 & 55 & 79 & 70 & 60 & 63 & 43,840 \\
\hline Sweden & 78.09 & 31 & 57 & 71 & 5 & 29 & 53 & 78 & 44,760 \\
\hline Norway & 78.04 & 31 & 64 & 69 & 8 & 50 & 35 & 55 & 66,520 \\
\hline Netherlands & 77.75 & 38 & 52 & 80 & 14 & 53 & 67 & 68 & 43,210 \\
\hline United Kingdom & 77.35 & 35 & 57 & 89 & 66 & 35 & 51 & 69 & 35,760 \\
\hline Denmark & 76.92 & 18 & 58 & 74 & 16 & 23 & 35 & 70 & 44,460 \\
\hline Iceland & 76.5 & 30 & 70 & 60 & 10 & 50 & 28 & 67 & 38,870 \\
\hline Slovenia & 76.43 & 71 & 40 & 27 & 19 & 88 & 49 & 48 & 28,130 \\
\hline Portugal & 75.8 & 63 & 48 & 27 & 31 & 99 & 28 & 33 & 25,360 \\
\hline Finland & 75.72 & 33 & 46 & 63 & 26 & 59 & 38 & 57 & 38,480 \\
\hline Estonia & 74.66 & 40 & 43 & 60 & 30 & 60 & 82 & 16 & 24,230 \\
\hline Slovakia & 74.45 & 100 & 40 & 52 & 100 & 51 & 77 & 28 & 25,500 \\
\hline Italy & 74.36 & 50 & 42 & 76 & 70 & 75 & 61 & 30 & 34,100 \\
\hline Greece & 73.28 & 60 & 41 & 35 & 57 & 100 & 45 & 50 & 25,630 \\
\hline France & 71.05 & 68 & 42 & 71 & 43 & 86 & 63 & 48 & 37,580 \\
\hline Poland & 69.53 & 68 & 31 & 60 & 64 & 93 & 38 & 29 & 22,300 \\
\hline Serbia & 69.13 & 86 & 52 & 25 & 43 & 92 & 52 & 28 & 12,020 \\
\hline Malta & 67.42 & 56 & 58 & 59 & 47 & 96 & 47 & 66 & 28,030 \\
\hline Belgium & 66.61 & 65 & 52 & 75 & 54 & 94 & 82 & 57 & 40,280 \\
\hline Latvia & 64.05 & 44 & 23 & 70 & 9 & 63 & 69 & 13 & 22,970 \\
\hline Bulgaria & 64.01 & 70 & 43 & 30 & 40 & 85 & 69 & 16 & 15,200 \\
\hline Croatia & 62.23 & 73 & 40 & 33 & 40 & 80 & 58 & 33 & 20,370 \\
\hline Lithuania & 61.26 & 42 & 35 & 60 & 19 & 65 & 82 & 16 & 24,500 \\
\hline Albania & 54.73 & 90 & 45 & 20 & 80 & 70 & 61 & 15 & 10,520 \\
\hline Russia & 53.45 & 93 & 33 & 39 & 36 & 95 & 81 & 20 & 23,200 \\
\hline Romania & 50.52 & 90 & 32 & 30 & 42 & 90 & 52 & 20 & 18,060 \\
\hline
\end{tabular}

\section{Copyrights}

Copyright for this article is retained by the author(s), with first publication rights granted to the journal.

This is an open-access article distributed under the terms and conditions of the Creative Commons Attribution license (http://creativecommons.org/licenses/by/3.0/). 